\title{
Variable coronary vasomotor responses to acetylcholine in patients with normal coronary arteriograms: evidence for localised endothelial dysfunction
}

\author{
D Tousoulis, G Davies, D C Lefroy, A W Haider, T Crake
}

\begin{abstract}
Objective-The vasomotor responses of the epicardial coronary arteries to acetylcholine were examined in patients with normal coronary arteries and chest pain.
\end{abstract} Design-Quantitative angiography was used to measure minimum lumen diameter of proximal and distal coronary artery segments at baseline, during intracoronary infusion of acetylcholine $\left(10^{-7}-10^{-3}\right.$ mol/1), and following an intracoronary bolus $(2 \mathrm{mg}$ ) of isosorbide dinitrate.

Patients-Coronary arteriograms were obtained in 15 patients (mean (SEM) age 48 (10) years) with normal coronary arteries and chest pain.

Main results-In response to the low concentrations of acetylcholine $\left(10^{-7}-10^{-6}\right.$ mol/1) 20 (61\%) distal and 11 (41\%) proximal segments showed dilatation (group 1), whereas $13(39 \%)$ distal segments and $14(52 \%)$ proximal segments showed constriction (group 2) $(\mathbf{P}<0.05 v$ group 1). In group 1, the maximum dilatation induced by acetylcholine in the proximal and distal segments was $7 \cdot 83(1 \cdot 19) \%$ and 11.6 $(2 \cdot 2) \%$ respectively. In group 2 , the maximum constriction at higher concentration was $16.55(3.3) \%$ and $33 \cdot 11(11.63) \%$ in the proximal and distal segments respectively. The two different patterns of the vasomotor response coexisted in eight (53\%) of the 15 patients. Intracoronary isosorbide dinitrate caused a greater increase in the coronary luminal diameter of distal segments than in proximal segments in group $1(25.63(5 \cdot 16) \% v$ $12.43(3.48) \%, P<0.01)$ but not in group 2 $(12.65(2.53) \%$ v $10.82(3.33) \%$.

Conclusions-Constriction and dilatation may occur in proximal and distal coronary artery segments, suggesting local areas of endothelial dysfunction, in response to acetylcholine in patients with chest pain and angiographically normal coronary arteries.

(Heart 1996;75:261-266)

Keywords: acetylcholine; endothelium; vasoconstriction; vasodilation

In patients with angiographically normal epicardial coronary arteries intracoronary acetylcholine causes coronary artery dilatation..$^{1-3}$ Experimental and clinical studies have shown that epicardial coronary artery dilatation is due to the release of nitric oxide in response to acetylcholine. ${ }^{46}$ In patients with atheromatous coronary arteries acetylcholine causes coronary artery constriction even at low doses ${ }^{3}$ 7-9 and the coronary artery responses to acetylcholine are dependent on the patient's characteristics and the extent of coronary atherosclerosis. ${ }^{1011}$ Experimental studies have supported these findings and it has consequently been argued that dilatation of a coronary artery in response to acetylcholine is consistent with normal endothelial function and constriction with endothelial dysfunction. ${ }^{12-14}$

Other studies have shown that in patients with chest pain and normal coronary arteries the vasodilator response to acetylcholine may be attenuated or vasoconstriction may even occur. ${ }^{15-16}$ Furthermore, El-Tamimi et al. ${ }^{17}$ have recently reported that in patients with coronary artery disease both localised dilatation and constriction at a given dose of acetylcholine can be observed in the same atheromatous vessel suggesting that in these arteries there are localised areas with normal endothelial function.

The effects of acetylcholine in normal coronary arteries seem to be dose dependent, constriction occurs at high dose in vessels dilated at lower doses and the effects of a particular dose seem to vary between patients. ${ }^{26}$ Localised dilatation and constriction at a given dose in the same coronary artery has never been reported in patients with angiographically normal coronary arteries. In this study we examined the segmental coronary vasomotor effects of acetylcholine in patients with chest pain and normal coronary arteriograms.

\section{Patients and methods}

Fifteen (six men; mean (SEM) (range) age 48 (10) (32-68) years) consecutive patients with a history of chest pain in exertion and angiographically normal coronary arteries were studied. Four patients had a positive treadmill exercise test $(\geqslant 0.1 \mathrm{mV}$ ST segment depression between 5 and 7 METS using the modified Bruce protocol) (table 1). Patients were allowed to use only sublingual glyceryl trinitrate as necessary, but no study was performed within $3 \mathrm{~h}$ of administration of the drug.

Patients were excluded fro the study if they had diabetes mellitus, left ventricular hypertrophy (as assessed by echocardiography), left ventricular dysfunction (left ventricular ejec- 
Table 1 Clinical characteristics of the patients

\begin{tabular}{|c|c|c|c|c|c|c|c|}
\hline Patient no & $\begin{array}{l}\text { Age } \\
\text { (years) }\end{array}$ & Sex & Hypertension & Smoking & $\begin{array}{l}\text { Family history } \\
\text { of } C A D\end{array}$ & Hypercholesterolaemia & $\begin{array}{l}\text { Exercise test } \\
\text { result }\end{array}$ \\
\hline 1 & 45 & F & + & - & + & - & tve \\
\hline 2 & 60 & $\mathrm{~F}$ & + & - & - & - & -ve \\
\hline 3 & 41 & $\mathrm{~F}$ & - & + & + & - & -ve \\
\hline 4 & 49 & $\mathbf{M}$ & - & + & - & - & $-\mathrm{ve}$ \\
\hline 5 & 46 & $\mathbf{M}$ & - & - & + & + & -ve \\
\hline 6 & 48 & $\mathbf{M}$ & - & - & + & - & -ve \\
\hline 7 & 58 & $\mathbf{F}$ & - & + & - & - & $-\mathrm{ve}$ \\
\hline 8 & 59 & $F$ & - & - & + & - & -ve \\
\hline 9 & 33 & $\mathbf{M}$ & - & - & + & - & -ve \\
\hline 10 & 43 & $\mathbf{M}$ & - & + & + & - & -ve \\
\hline 11 & 32 & M & - & - & + & - & -ve \\
\hline 12 & 42 & $\mathbf{M}$ & + & - & - & - & tve \\
\hline 13 & 68 & $\mathbf{M}$ & - & + & - & - & tve \\
\hline 14 & 46 & $\mathrm{~F}$ & - & + & - & - & -ve \\
\hline 15 & 47 & $\mathbf{F}$ & - & + & - & + & tve \\
\hline
\end{tabular}

CAD, coronary artery disease; +, present; -, absent; +ve, positive; -ve, negative.

tion fraction $<50 \%$ ), or valvular heart disease. Patients with a clinical history that suggested coronary artery spasm or with ergonovineinduced coronary artery spasm were excluded. Patients had at least one of the following risk factors for coronary artery disease: (a) hypercholesterolaemia: defined as a fasting serum cholesterol $>5.69 \mathrm{mmol} / 1$ ( $>220$ $\mathrm{mg} / \mathrm{dl}$ ) before treatment; (b) hypertension: requiring antihypertensive drug treatment by the primary physician; $(c)$ cigarette smoking: patients who were currently smoking or had stopped less than 3 months before the study; and (d) family history: a parent or sibling under the age of 60 years of the patient who had documented evidence of coronary artery disease such as a history of myocardial infarction, coronary artery bypass surgery, angina pectoris, sudden death, or angiographically documented coronary artery disease. ${ }^{18}$

The study protocol was approved by the Research Ethics Committee of the Hammersmith Hospital and informed written consent was obtained from all patients.

\section{STUDY PROTOCOL}

Two electrocardiogram leads were monitored continuously throughout the study. Coronary arteriography was performed through the right femoral artery using 8 French Judkins catheters. Femoral arterial blood pressure and heart rate were recorded during the last $30 \mathrm{~s}$ of each infusion period. Following the diagnostic study, an optimal radiographic projection was chosen to visualise the coronary arteries to be studied, and the position of the image intensifier was subsequently kept constant. The left coronary artery only was studied in nine patients, the right coronary artery only in four, the right and left coronary arteries in two. Infusions were administered through the Judkins catheters at room temperature at a rate of $1 \mathrm{ml} / \mathrm{min}$ using a syringe pump (Perfusor; Braun-Melsungen, Germany). All patients received a single $2 \mathrm{~min}$ infusion of vehicle solution $(0.9 \%$ saline), followed by 2 $\mathrm{min}$ infusions of acetylcholine $(1 \mathrm{ml} / \mathrm{min})$ in incremental intracoronary concentrations from $10^{-7}$ to $10^{-5} \mathrm{~mol} / \mathrm{l}$ in two patients, to $10^{-4} \mathrm{~mol} / 1$ in four, and to $10^{-3} \mathrm{~mol} / 1$ in nine, followed by an intracoronary bolus of isosorbide dinitrate ( $2 \mathrm{mg}$ in $2 \mathrm{ml}$ saline).

Coronary angiography was performed with a hand injection of non-ionic contrast medium $(6-8 \mathrm{ml})$ at baseline, after each infusion, and 2 min after isosorbide dinitrate. The catheter was emptied before each angiogram to avoid bolus administration of infused solutions.

\section{QUANTITATIVE CORONARY ANGIOGRAPHY}

The arterial segments in an end diastolic frame from each arteriogram were analysed in random order using quantitative computerised analysis with an automated edge contour detection analysis system (Computerised Angiographic Analysis System, Version 2V2; Pie Data Medical, Maastricht). ${ }^{19} 20$ The angiographic catheter was used as a scaling device and this together with the pincushion distortion correction allowed the diameters to be recorded as absolute values. The diameter of angiographically proximal and distal segments was measured from the arteriograms recorded at baseline and after saline, acetylcholine and nitrate administration. The proximal left anterior descending coronary artery diameter was measured just beyond the origin of the artery and the distal diameter was measured just distal to its second diagonal branch; the proximal left circumflex coronary artery diameter was measured just beyond the origin of the artery and the distal diameter just beyond the origin of the second marginal branch; the proximal right coronary artery diameter was measured just beyond the origin of the artery and the distal diameter just beyond the origin of posterior descending branch. In the 15 patients, 11 left and six right coronary arteries were studied. Eleven proximal and distal left anterior descending coronary artery segments were analysed. Ten proximal left circumflex (in one patient the image quality of the left circumflex was not suitable for analysis) and 14 distal left circumflex segments were analysed; in three patients with a dominant left circumflex coronary artery an additional distal segment in the second marginal branch was analysed. Six proximal and eight distal right coronary artery segments were analysed; in two patients with pronounced dominant right coronary arteries one additional distal segment was analysed.

Quantitative analysis of coronary arteriograms was carried out by two independent observers, who blindly reanalysed the films at a remote time for reproducibility of the method. No significant intra- or inter-observer 
Table 2 Reactivity of proximal and distal segments in patients with normal coronary arteries to intracoronary administration of acetylcholine and nitrates

\begin{tabular}{|c|c|c|c|c|}
\hline & \multicolumn{4}{|c|}{ Minimum luminal diameter $(\mathrm{mm})$} \\
\hline & \multicolumn{2}{|l|}{ Group 1} & \multicolumn{2}{|l|}{ Group 2} \\
\hline & $\begin{array}{l}\text { Proximal } \\
\text { segments }\end{array}$ & $\begin{array}{l}\text { Distal } \\
\text { segments }\end{array}$ & $\begin{array}{l}\text { Proximal } \\
\text { segments }\end{array}$ & $\begin{array}{l}\text { Distal } \\
\text { segments }\end{array}$ \\
\hline Baseline & $3 \cdot 53(0 \cdot 2)$ & $1.32(0.07)$ & $3 \cdot 15(0 \cdot 1)$ & $1 \cdot 51(0.06)$ \\
\hline Saline & $3 \cdot 58(0 \cdot 2)$ & $1.31(0.07)$ & $3 \cdot 19(0 \cdot 1)$ & $1.53(0.05)$ \\
\hline \multicolumn{5}{|l|}{ Acetylcholine $(\mathrm{mol} / \mathrm{l})$} \\
\hline $10^{-7}$ & $3 \cdot 55(0 \cdot 2)$ & $1.39(0.07) \dagger$ & $2.94(0 \cdot 1)^{\star}$ & $1.35(0.05)^{\star}$ \\
\hline $10^{-6}$ & $3 \cdot 71(0 \cdot 2) \dagger$ & $1.48(0.08)^{\star}$ & $2 \cdot 95(0 \cdot 1)^{\star}$ & $1.36(0.05)^{\star}$ \\
\hline $10^{-5}$ & $3 \cdot 81(0 \cdot 2)^{\star}$ & $1.41(0.08) \dagger$ & $2 \cdot 87(0 \cdot 1)^{\star}$ & $1.28(0.06)^{\star}$ \\
\hline $10^{-4}$ & $3 \cdot 67(0 \cdot 2)$ & $1.29(0.08)$ & $2 \cdot 83(0 \cdot 2)^{\star}$ & $1.26(0.05)^{\star}$ \\
\hline $10^{-3}$ & $3.60(0.3)$ & $1.04(0.13) \dagger$ & $2 \cdot 63(0 \cdot 2)^{\star}$ & $0.97(0.19)^{\star}$ \\
\hline ISDN & $3.93(0.3)^{\star}$ & $1.62(0 \cdot 10)^{\star}$ & $3.52(0 \cdot 2)^{\star}$ & $1.68(0.07)^{\star}$ \\
\hline
\end{tabular}

Values are mean $(S E M) .{ }^{\star} P<0.01$ versus baseline; $\nmid P<0.05$ versus baseline. ISDN, isosorbide dinitrate.
CORONARY ARTERY DIAMETER CHANGES IN RESPONSE TO ACETYLCHOLINE AND NITRATE During saline infusion no significant changes were observed in the proximal and distal segments (table 2).

Three patterns of response to the low doses of acetylcholine $\left(10^{-7}-10^{-6} \mathrm{~mol} / \mathrm{l}\right)$ were observed; constriction only in three patients, dilatation only in four, and constriction and dilatation in eight (in the same vessel in six and in different vessels in two). At these low concentrations of acetylcholine 33 distal and 27 proximal segments were studied and coronary artery segments were divided into two groups, according to their response to low doses of acetylcholine (table 2). Twenty $(61 \%)$ of 33 distal and 11 (41\%) of 27 proximal segments dilated $\geqslant 5 \%$ (group 1 ), and 13 $(39 \%)$ of 33 distal segments and $14(52 \%)$ of 27 proximal segments constricted $\geqslant 5 \%$ (group 2). Two proximal segments did not change. The frequency of dilatation of distal vessels was greater than constriction $(\mathrm{P}<$ $0.05)$. The maximum magnitude of dilatation in group 1 in the proximal segments $(7.83$ $(1 \cdot 19) \%)$ was observed at $10^{-5} \mathrm{~mol} / \mathrm{l}$ and that in the distal segments $(11.6(2 \cdot 2) \%)$ at $10^{-6}$ $\mathrm{mol} / \mathrm{l}$ (figs 1 and 2 ).

At maximum acetylcholine concentration $\left(10^{-3} \mathrm{~mol} / \mathrm{l}\right)$ in group 1 segments, eight $(73 \%)$ of 11 distal and two (40\%) of five proximal segments constricted $(P<0.001$ compared with the low concentration response) and the remainder dilated or did not change. In group 2 , all distal $(n=9)$ and proximal $(n=9)$ segments constricted further at $10^{-3} \mathrm{~mol} / 1$. During the maximum dose of acetylcholine constriction was greater in group 2 segments than in group 1 (proximal segments -16.55 (3.3)\% v-0.7 (2.63)\%, P < 0.05; distal segments - 33.11 (11.63)\% v - 15.78 (8.2)\%) and greater in distal than in proximal segments $(P<0.05)$ for both groups (fig 2$)$.

Increase in the coronary luminal diameter caused by intracoronary isosorbide dinitrate was greater in distal segments than in proximal segments in group $1(25 \cdot 63(5 \cdot 16) \%$ v 12.43 $(3.48) \%, P<0.01)$ but not in group $2(12.65$ $(2.53) \% v 10.82(3.33) \%, \mathrm{P}=$ not significant $)$ (fig 2). In three patients focal constriction ( $>30 \%$ baseline minimum luminal reduction)
Figure 1 Dose dependent responses to acetylcholine (mean (SEM) changes in segment diameter in absolute measurements $(\mathrm{mm})$ ) of the proximal and distal segments $(+P<$ $0.05 ;{ }^{\star} P<0.01$ versus baseline). Two patterns of vasomotion were observed in response to low acetylcholine concentrations in proximal and distal segments $\left(10^{-7}-10^{-6} \mathrm{~mol} / \mathrm{l}\right)$ : dilatation (group 1) or constriction (group 2). NS, normal saline; ISDN, isosorbide dinitrate.

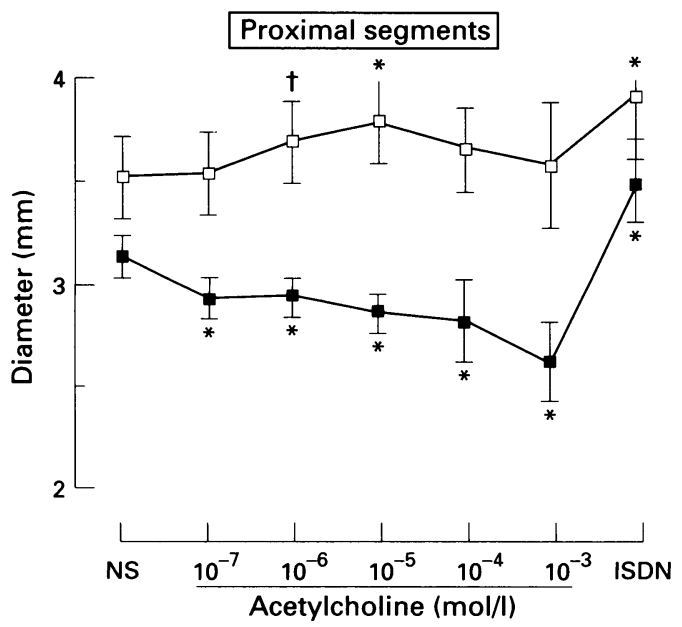


Figure 2 Dose dependent responses to acetylcholine (mean (SEM) per cent change in coronary luminal diameter from baseline) of the proximal and distal segments $\left(+P<0.05 ;{ }^{\star} P<\right.$ 0.01 versus saline). Two patterns of vasomotion were observed in response to low acetylcholine concentrations in proximal and distal segments $\left(10^{-7}-10^{-6}\right.$ molll): dilatation (group 1) or constriction (group 2). Values in parentheses are numbers of segments studied. Abbreviations as given in fig 1 .
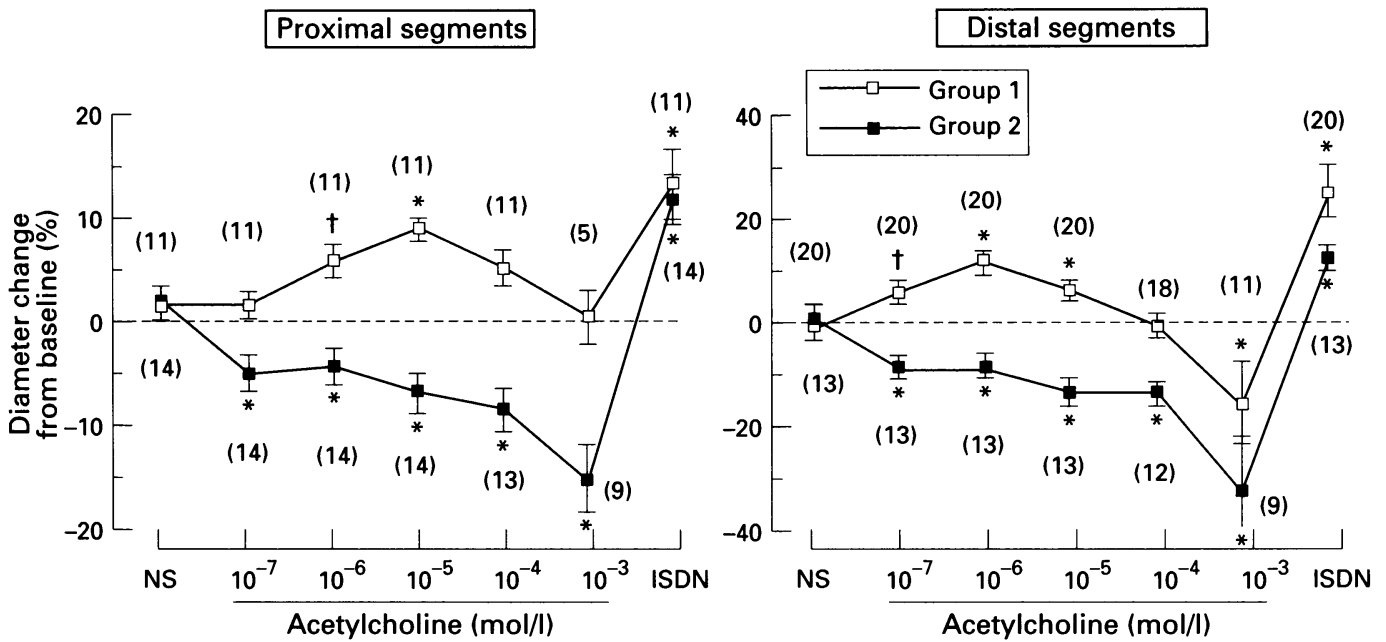

reversed by nitrates was observed in five segments (four mid, and one distal) at sites which were not initially selected for analysis. At these segments the minimum luminal diameter was $2.26(0.25) \mathrm{mm}$ at baseline, $0.66(0.27) \mathrm{mm}$ (mean reduction $66(13) \%$ ) after acetylcholine $(\mathrm{P}<0.05)$, and $2.36(0.25) \mathrm{mm}$ after nitrate administration.

\section{Discussion}

In patients with chest pain and angiographically normal coronary arteries the effects of intracoronary acetylcholine are variable. Constriction and dilatation coexisted in most patients not only in different coronary artery branches but also in different segments of the same branch. All segments dilated in response to isosorbide dinitrate, a direct acting smooth muscle dilator. These results suggest that in patients with chest pain most angiographically normal coronary arteries have areas of dysfunctional endothelium. ${ }^{10}$

\section{EFFECTS OF ACETYLCHOLINE IN ANGIOGRAPHICALLY NORMAL CORONARY ARTERIES}

Acetylcholine is an endothelium dependent vasodilator as well as a potent vascular smooth muscle vasoconstrictor. ${ }^{421}$ Previous clinical studies $^{3}$ have shown that angiographically normal coronary arteries dilate but atherosclerotic coronary arteries constrict in response to the intracoronary infusion of acetylcholine. Werns et $a l^{8}$ found that acetylcholine caused dilatation of angiographically normal coronary arteries and constriction of angiographically normal segments in patients with coronary artery disease suggesting that these normal segments are functionally abnormal. An interaction between cardiovascular risk factors and endothelial dysfunction has been reported previously. Acetylcholine has been shown to induce vasoconstriction in patients with normal coronary arteries and hypercholesterolaemia with increased plasma concentrations of low density lipoproteins, ${ }^{101122}$ although these authors did not investigate the segmental effects of acetylcholine in their patients. Experimental studies have shown that choles- terol fed animals develop selective attenuation of endothelium dependent vasodilatation before and after developing histological evidence of frank atherosclerosis. ${ }^{12} 13$ Acute and chronic increase in blood pressure leads to impairment of endothelium dependent vasodilatation, perhaps due to endothelial injury. ${ }^{23-25}$ may have intimal thickening of variable degree and therefore will produce a variable response to vasoactive substances.

Endothelial dysfunction appears very early in the development of coronary artery disease. ${ }^{11}$ Our observations are consistent with a patchy impairment of endothelial function due to early atherosclerosis, so that the direct smooth muscle constrictor effect predominates in some segments. Such atherosclerosis cannot be detected by coronary angiography. In our study it is likely, therefore, that the smooth coronary segments that constricted in response to acetylcholine had early atherosclerosis which was not detectable by angiography.

\section{PROXIMAL AND DISTAL SEGMENT RESPONSES} TO ACETYLCHOLINE AND ENDOTHELIAL

FUNCTION

Although in the present study acetylcholine caused vasodilatation and vasoconstriction in proximal and distal segments, the percentage response was significantly greater in distal segments. These results are consistent with previous studies showing enhanced distal vasoconstriction in response to serotonin, ${ }^{20}$ acetylcholine, ${ }^{9}$ and ergonovine. ${ }^{26}$ The mechanism underlying this variable magnitude of response of the coronary arteries of different sizes to certain stimuli is unclear. This differential response may also be modified by the distribution of atherosclerosis which is more prevalent and severe in proximal segments.

The observed response to acetylcholine is consistent with a patchy impairment of endothelial function due to atherosclerosis so that the direct smooth muscle constriction effect predominates in some segments. It can also be explained by an increased sensitivity of the vascular smooth muscle in the region of atherosclerosis to acetylcholine, a defect in the Patients with angiographically normal arteries 
coupling mechanisms between endothelium derived relaxing factor and smooth muscle cells, or an increased release of endothelium derived vasoconstricting factors.

\section{CLINICAL IMPLICATIONS}

The segmental heterogeneity of the response of apparently normal coronary arteries may be a means of detecting early atherosclerosis or an alteration of endothelial function which precedes the development of atherosclerosis, as suggested by other studies. ${ }^{11}$ The technique is safe and rapidly performed and does not require instrumentation of the coronary arteries as do other techniques for detecting early atherosclerosis such as intracoronary ultrasound and therefore the risk of vascular trauma is reduced. ${ }^{27}{ }^{28} \mathrm{It}$ also permits examination of the entire artery including the distal branches. Although detection of early atherosclerosis may not be immediately relevant to a patient's symptoms, it could be of prognostic significance. Angiographically normal coronary arteries are frequently found in patients with chest pain undergoing cardiac catheterisation. ${ }^{29}$ Our study has shown that at least some of these patients may have coronary artery segments which behave abnormally in response to acetylcholine; indeed, these segments have the same response as atheromatous coronary artery segments. ${ }^{17}$ The clinical implications of this finding remain speculative at the present time and follow up studies are required to ascertain whether such patients are at increased risk of developing flow limiting coronary stenosis or coronary thrombosis perhaps at the sites of abnormal endothelial behaviour. Further studies will determine whether risk factor modification results in restoration of normal endothelial function.

\section{STUDY LIMITATIONS}

Our study population was relatively small and represents a selected group of patients with chest pain syndromes referred for cardiological assessment who had angiographically normal coronary arteriograms. The coronary arteries were assessed by coronary arteriography and they were therefore angiographically "normal". It must be emphasised that coronary arteriography has important limitations in the detection of early coronary atherosclerosis and possibly the pattern of response to acetylcholine that we observed was due to localised areas of early atherosclerosis. In this respect intravascular ultrasound may have been a useful method to identify such areas of early atheroma.

\section{Conclusions}

In patients with chest pain and normal coronary arteriograms the response to acetylcholine is heterogeneous, not only between patients, but between vessels in an individual patient and between segments in an individual vessel. This evidence of patchy endothelial dysfunction may be indicative of early underlying atherosclerosis which cannot be detected by coronary angiography.
1 Yasue $\mathrm{H}$, Matsuyama K, Matsuyama K, Okumura K, Morikami Y, Ogawa H. Responses of angiographically normal human coronary arteries to intracoronary injection of acetylcholine by age and segment. Possible role of early atherosclerosis. Circulation 1990;81:482-90.

2 Egashira $\mathrm{K}$, Inou $\mathrm{T}$, Hirooka $\mathrm{Y}$, Yamada A, Urabe $\mathrm{Y}$, Takeshita A. Evidence of endothelium-dependen vasodilation in patients with angina pectoris and norma coronary angiograms. N Engl f Med 1993;328:1659-64.

3 Ludmer PL, Selwyn AP, Shook TL, Wayne RR, Mudge GH, Alexander RW, et al. Paradoxical vasoconstriction induced by acetylcholine in atherosclerotic coronary arteries. N Engl F Med 1986;315:1046-51.

4 Furchgott RF, Zawadzki JV. The obligatory role of the endothelial cells in the relaxation of arterial smooth muscle by acetylcholine. Nature 1980;288:373-6.

5 Palmer RM, Ferrige AG, Moncada S. Nitric oxide release accounts for the biological activity of endothelial-derived accounts for the biological activity of endo

6 Quyyumi AA, Cannon RO, Panza JA, Diodato JG, Epstein SE. Endothelial dysfunction in patients with chest pain and normal coronary arteries. Circulation 1992;86 1864-71

7 Hodgson JMcB, Marshall J. Direct vasoconstriction and endothelium-dependent vasodilation: mechanisms of acetylcholine effects on coronary flow and arterial diameter in patients with nonstenotic coronary arteries. Circulation 1989;79:1043-51.

8 Werns SW, Walton JA, Hsia HH, Nabel EG, Sans ML Pitt B. Evidence of endothelium dysfunction in angiographically normal coronary arteries in patients with coronary artery disease. Circulation 1989;79:287-91.

9 Newman CM, Maseri A, Hackett D, El-Tamimi HM, Davies GJ. Response of angiographically normal and atherosclerotic left anterior descending coronary arteries to acetylcholine. Am $¥$ Cardiol 1990;66:1070-6.

10 Vita JA, Treasure CB, Nabel EG, McLenachan JM, Fish DR, Yeung AC, et al. Coronary vasomotor response to acetylcholine relates to risk factors for coronary artery disease. Circulation 1990;81:491-7.

11 Zeiher AM, Drexler H, Wollschlager H, Just $H$ Modulation of coronary vasomotor tone in humans. Progressive dysfunction with different early stages of coronary atherosclerosis. Circulation 1991;83:391-401.

12 Andrews HE, Bruckdorfer KR, Dunn RC, Jacobs M. Lowdensity lipoproteins inhibit endothelium-dependent relaxation in rabbit aorta. Nature 1987;327:237-9.

13 Venbeuren TJ, Jordaens FH, Zonnekeyn LLO, Van Hove CE, Coene MC, Herman AG. Effects of hypercholesterolemia on vascular reactivity in the rabbit. Circ Res 1986;58:552-64.

14 Shimokawa H, Vanhoutte PM. Impaired endotheliumdependent relaxation to aggregating platelets and related vasoactive substances in porcine coronary arteries in vasoactive substances in porcine coronary arteries in
hypercholesterolemia and atherosclerosis. Circ Res 1989; 64:900-14.

15 Motz W, Vogt M, Rabenau O, Scheler S, Luckhoff A, Strauer BE. Evidence of endothelial dysfunction in coronary resistance vessels in patients with angina pectoris and normal coronary arteries. Am $\mathcal{F}$ Cardiol 1991;68: 996-1003.

16 Vrints CJM, Bult H, Hitter E, Herman AG, Snoeck J. Impaired endothelium-dependent cholinergic coronary vasodilation in patients with angina and normal coronary arteriograms. f Am Coll Cardiol 1992;19:21-31.

17 El Tamimi H, Mansour M, Wargorich TJ, Hill JA Kerensky RA, Conti RC, et al. Constrictor and dilator responses to intracoronary acetylcholine in adjacent segments of the same coronary artery in patients with coronary artery disease. Endothelial function revisited. Circulation 1994;89:45-51.

18 Barrett-Connor E, Khaw KT. Family history of heart attack as an independent predictor of death due to cardiovascular disease. Circulation 1984;69:1065-9.

19 Reiber JHC, Serruys PW, Koouman C, Wijns W, Slager C Gerbrands JJ, et al. Assessment of short-, medium, and long-term variations in arterial dimensions from computer-assisted quantitation of coronary cineangiograms. puter-assisted quantitation

20 Tousoulis D, Davies G, McFadden E, Clarke J, Kaski JC, Maseri A. Coronary vasomotor effects of serotonin in patients with angina: relationship to coronary stenosis morphology. Circulation 1993;88:1518-26.

21 Furchgott RF. Role of endothelium in responses of vascular smooth muscle. Circ Res 1983;53:557-73.

22 Casino PR, Kilcoyne CM, Quyyumi AA, Hoeg JM, Panza JA. Investigation of decreased availability of nitric oxide precursor as a mechanism responsible for impaired endothelium-dependent vasodilation in hypercholesterolemic patients. F Am Coll Cardiol 1994;23:844-50.

23 Panza JA, Quyyumi AA, Bruch JE Jr, Epstein SE. Abnormal endothelium-dependent vascular relaxation in patients with essential hypertension. $N$ Engl $f$ Med 1990;323:22-7.

24 Panza JA, Casino PR, Kilcoyne CM, Quyyumi AA. Role of endothelium-derived nitric oxide in the abnormal endothelium-dependent vascular relaxation of patients

with essential hypertension. Circulation 1993;87:1468-74. Luscher TF, Vanhoutte PM, Raij L. Antihypertensive treatment normalizes decreased endothelium-dependen relaxations in rats with salt-induced

26 Tousoulis D, Kaski JC, Bogaty P, Crea F, Gavrielides S, Galassi AR, et al. Reactivity of proximal and distal angio- 
graphically normal and stenotic coronary segments in chronic stable angina pectoris. Am f Cardiol 1991;67: $1195-200$

27 Nissen SE, Gurley JC, Grines CL, Booth DC, McClure R, Berk $M$, et al. Intravascular ultrasound assessment of lumen size and wall morphology in normal subjects and patients with coronary artery disease. Circulation 1991; 84:1087-99.
28 St Goar FG, Pinto FJ, Alderman EL, Fitzgerald PJ, Stadius $\mathrm{ML}$, Popp RL. Intravascular ultrasound imaging of angiographically normal coronary arteries as in vivo comparison with quantitative angiography. $₹ \mathrm{Am}$ Coll Cardio 1991;18:952-8.

29 Cannon RO, Epstein SE. "Microvascular angina" as a cause of chest pain with angiographically normal coronary arteries. Am $\mathcal{F}$ Cardiol 1988;61:1338-43.

\title{
SHORT CASES IN CARDIOLOGY
}

\section{Interventricular septal hydatid cyst presenting as complete heart block}

\author{
Dinesh K Agarwal, Reshma Agarwal, Satish P Barthwal
}

\begin{abstract}
A 25 year old man presented with StokesAdams attacks, which he had had for 18 months. His pulse rate was 40 per minute and his blood pressure was $140 / 60 \mathrm{~mm} \mathrm{Hg}$. Cardiac examination showed a grade $2 / 6$ mid-ejection systolic murmur at the left sternal border with no signs of cardiac failure. Pulmonary and neurological examinations were normal. The electrocardiogram showed complete heart block. The chest $x$ ray and haemogram were normal. He was treated with temporary ventricular pacing. Colour Doppler echocardiography (Vingmed CFM 725) showed a homogeneous cystic mass (diameter $2.8 \mathrm{~cm}$ ) with smooth rims located in the middle third of the interventricular septum (figure). There was no gradient across left ventricular or right ventricular outflow tracts. Abdominal ultrasound showed a cyst (diameter $5.3 \mathrm{~cm}$ ) with internal echogenic shadows in the posterior segment of right hepatic lobe. A computed tomogram of the abdomen showed similar findings.

The indirect haemagglutination test for
\end{abstract}

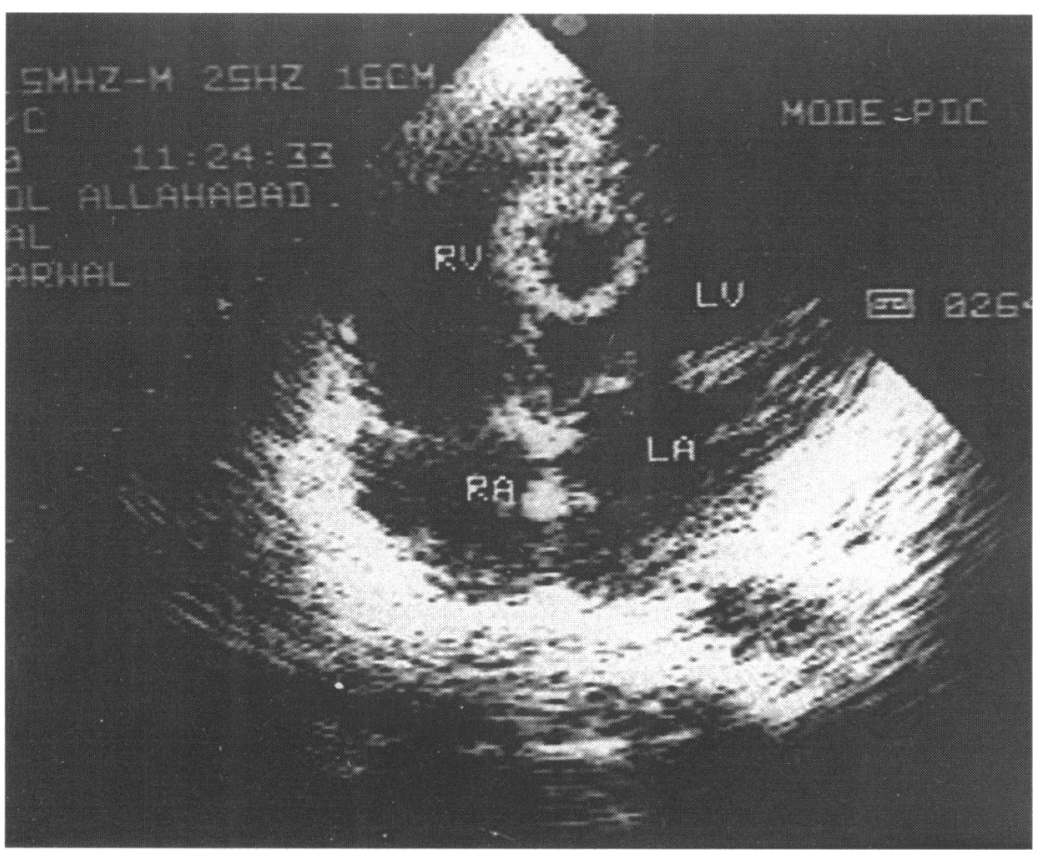

Apical four chamber echocardiogram showing a rounded cystic mass in the interventricular septum. echinococcus was positive (1/640). The hepatic cyst was drained and injected with hypertonic saline. The cyst contained scolices of echinococcus. He had been treated with albendazole for 2 weeks before the hepatic cyst was drained. This dose $(5 \mathrm{mg} / \mathrm{kg}$ twice daily) was continued for another 2 weeks. Two more courses were repeated after an interval of 3 weeks.

The patient refused cardiac surgery. A permanent pacemaker (VVI multiprogrammable) was implanted because he was dependent on the temporary pacemaker. When the patient was reassessed after 6 months and after 2 years he was symptom free. The patient was reassessed at one year when he was still pacemaker dependent and there was no change in the size of the cyst on the echocardiogram.

Echinococcosis in the heart is uncommon and a cyst in the interventricular septum is rarer still, accounting for only $2-9 \%$ of all cardiac cases. ${ }^{1-2}$ They occur in the pericardium or free wall of left ventricle in $50 \%-77 \%$ cases. ${ }^{13}$ In our patient the hydatid cyst was located in the interventricular septum and caused syncopal attacks owing to complete heart block. Another similar case has been reported. ${ }^{2}$ We agree with the earlier reports ${ }^{34}$ that cross sectional echocardiography is the most reliable method of diagnosing an intraseptal hydatid cyst. In our patient the scolices found in the fluid from the hepatic cyst was further evidence that the cyst in the interventricular septum was hydatid. This tended to exclude the other possibility of a mesothelioma.

Surgical removal of the cardiac cyst remains the best treatment. ${ }^{2}$ Where this is not feasible, however, patients can be treated satisfactorily with repeated courses of albendazole and the supportive measures used in our patient.

1 Desnos M, Brochet E, Cristofini P, et al. Polyvisceral echinococcosis with cardiac involvement imaged by two dimensional echocardiography, computed tomograph and nuclear magnetic resonance imaging. Am $\mathcal{f}$ Cardiol 1987;59:383-5.

2 Ottino G, Villani M, De Paulis R, Trucco G, Viara J Restoration of atrioventricular conduction after surgical removal of a hydatid cyst of the intraventricular septum. $\mathcal{f}$ Thorac Cardiovasc Surg 1987;93:144-7.

3 Lanzoni AM, Barrios V, Moya JL, Epeldegui A, Celemin D. Dynamic left ventricular outflow obstruction cause by cardiac echinococcosis. Am Heart f 1992;124:1083-5. 4 Kontopoulos AG, Avramides MJ, Athyros VG. Diagnosis, treatment, and long-term follow up of a patient with hydatid cyst of the left ventricle. Br Heart f 1994;72:592. 